\title{
Türkiye’nin Coğrafi Bilgi Sistemleri Tabanlı Finansal Risk Haritası
}

\author{
Halil İbrahim Zeybek, Handan Çam*, Alper Veli Çam
}

öz

Coğrafi Bilgi Sistemleri (CBS) grafik ve grafik olmayan verilerin birebir iliş̧kili olduğu sistemlerdir ve son zamanlarda finans alanında da kullanılmaya başlanmıştır. Bu çalışmanın amacı; finansal riski belirleyen parametreleri kullanarak, Türkiye'nin finansal risk haritasını CBS ile oluşturmaktır. Çalışmada 2016 yılına ait İstatistiki Bölge Birimleri Sınıflandırması (IBBSS) düzey 2 verileri kullanılmıștır. Literatürde tanımlayıcı istatistiksel yöntemler kullanılarak yapılan risk analizler' yüzeysel ve statik sonuçlar vermektedir. Bu bağlamda GSMH, işsizlik oranı, enflasyon oranı, batık kredi oranı ve sorunlu kredi kartları gibi parametreler kullanılarak Türkiye'nin mevcut finansal risk haritası mekânsal regresyon analizi ile oluşturulmuştur. Elde edilen bulgular daha dinamik, daha anlamlı ve görsel sonuçlar ortaya çıkarmıştır. Kullanılan yöntem itibariyle Türkiye'de alanında ilk CBD tabanlı finansal risk analizi yapılmıştır. Çalışmanın çıktılarından bir diğeri ise CBS tabanlı uygulamaların finans alanında rahatlıkla kullanılabileceğini ortaya koymasıdır.

Anahtar Kelimeler: CBS, Finansal Risk, Mekânsal Regresyon.

\section{Geographic Information Systems Based Financial Risk Map of Turkey}

\begin{abstract}
Geographic Information Systems (GIS) are systems in which graphics and non-graphical data are interrelated and can be easily used in the field of finance. The aim of this study is to create Turkey's financial risk map with GIS by using the parameters that determine Turkey's financial risk. In the study, the data for the year 2016 and the Statistical Region Units Classification (NUTS) level 2 were used. In the literature, risk analyzes using descriptive statistical methods give superficial and static results. In this context, the current financial risk map of Turkey was created by spatial regression analysis using parameters such as GNP, unemployment rate, inflation rate, problematic loans and problematic credit cards. Obtained findings reveal more dynamic, more meaningful and visual results. In the study, the first GIS based financial risk analysis was carried out in the field in Turkey. One of the outputs of the workshop is that the GIS-based applications can be easily used in finance.
\end{abstract}

Keywords: GIS, Financial Risk, Spatial Regression.

\section{Information of Author(s):}

Halil İbrahim Zeybek

DOI: $10.30801 /$ acin. 354960

ORCID: 0000-0002-4097-9076

hizeybek@omu.edu.tr

Ondokuz Mayıs Üniversitesi

Handan Çam (*) ORCID: 0000-0003-0982-2919

hcam@gumushane.edu.tr

Gümüşhane Üniversitesi, İ.İ.B.F. YBS Bölümü

Alper Veli Çam

ORCID: 0000-0001-6078-5186

alpercam@gumushane.edu.tr

Gümüşhane Üniversitesi, İ.İ.B.F. İşletme Bölümü

(*) Contact Author

Address: Gümüşhane Üniversitesi, İ.İ.B.F. YBS Bölümü No:419, Gümüşhane, Türkiye • Telephone Number: +90 0456 $2331229-2188$ 


\section{GİRIŞ}

CBS'nin dünyada konumsal bilgi ile ilgilenen kişi ve kurumlar tarafindan her alanda kullanılmaya başlanması, yeni çalışmaları ve uygulamaları da beraberinde getirmiştir. Bu açıdan CBS, bir taraftan konumsal bilgi sistemlerinin tümünü içeren bilimsel bir kavram, diğer taraftan konumsal bilgileri dijital yapıya kavuşturan bilgisayar tabanlı bir araç ve veri tabanı yönetim sistemidir (Yomralioglu, 2002). Bu sistem, coğrafi olaylara ait verilerin toplanmasını, depolanması, sınıflandırılmasını, güncelleştirilmesini, sentezlenmesini ve alternatif stratejiler üretilmesini kısa bir sürede yapabilen bir altyapıya sahiptir. Farklı bakış açılarına göre hazırlanan çalışmalar, CBS'nin tanınması ve kullanımının yaygınlaştırılması için önemlidir. Günümüzde farklı disiplinlere hizmette bulunan CBS'nin en önemli işlevlerinden birisi de çevresel problemlerin belirlenmesi ve bu problemlerin çözümüdür. Bu çevresel problemlerden biride riskin belirlenmesi ve ölçülmesidir.

Finansal açıdan risk; yapılan yatırımın geri dönmeme ihtimali yani beklenen getirinin gerçekleşen getiriden farklı olma olasılı̆̆ıdır (Jones, 1998). Finans teorisinde risk, kaynaklarına göre sınıflandırılmaktadır. Bunlar; sistematik risk, sistematik olmayan risk ve sistemik risktir. Sistematik risk; piyasa içerisindeki tüm menkul kıymetleri etkileyebilen, sistemden kaynaklanan ve firmanın kontrolü dışında meydana gelen risk olarak tanımlanmaktadır (Modigliani \& Fabozzi, 1992; Okka, 2010).

Sistematik riskin kaynağı piyasa aktörleri olduğu için firmaların ve ülkelerin bu risk konusunda bir tasarrufu yoktur. Sistematik riskin birçok unsuru finansal risk faktörlerini de içermektedir. Diğer taraftan bir ülkenin ekonomi ve finans yönetimindeki değişiklikler ülkedeki firmalar üzerinde önemli etkiler yapmaktadır (Hoti \& McAleer, 2005). Ülke riskini temel olarak politik, ekonomik ve finansal risk faktörleri oluşturmaktadır. Bu risk faktörleri arasında finansal risk faktörleri gerek işletmeler gerekse ülkeler açısından önemlidir. Finansal risk, para ile ilgili her türlü riski kapsamaktadır. Alacakların tahsil edilememesi, gelirlerin düşmesi, borçların ödenememesi, enflasyon, işsizlik gibi birçok değişken finansal risk unsurları arasında gösterilebilir (Altan vd., 2016). Bu risk unsurlarının bir bütün yerine, bütünü oluşturan parçalar açısından incelenmesi birçok avantajı beraberinde getirecektir. Örneğin bir ülkenin finansal riski belirlenirken, ilgili risk değerlerinin coğrafi açıdan bölgesel olarak ayrıştııılması, yatırımcılar ve ülkeler açısından daha dinamik analizler yapılmasına imkan verecektir.

İlgili literatür incelendiğinde finansal risk haritalarının ortaya çıkarılmasına ilişkin yapılan bazı çalışmalar mevcuttur. Cecchetti vd. (2010) çalışmalarında uluslararası bankacılık sektöründeki verileri kullanarak sistematik riske maruz kalmış ülkelerin risk haritasını çıkarmışlardır. Peggion vd. (2008), CBS ile risk değerleme üzerine bir çalışma geliştirmişlerdir. Colletaz vd. (2013), çalışmalarında benzer şekilde riske maruz değeri kullanarak risk haritası kullanmışlardır. Altan vd. (2016), Türkiye'de finansal risk haritasını çıkardıkları çalı̧̧malarında finansal risk faktörlerinin ortalamalarını kullanarak bir harita ortaya çıkarmaya çalışmışlardır. Bu çalışmalarda ortaya çıkarılan risk haritaları, CBS yöntemleri dışında daha çok grafiksel analizler yapılarak hazırlanmıştır. Bunun yanında CBS ve mekânsal regresyon analizlerinin kullanıldığı çalışmalarda mevcuttur. Çelik (2017), çalışmasında Türkiye'deki teşvik politikalarının etkinliğini araştırmada mekânsal regresyon analizi kullanmıştır. Baktemur ve Özmen (2017), çalışmalarında Avrupa Birliğine üye gelişmiş ülkelerde işsizlik yakınsamaların analizinde mekânsal ekonometri kullanmışlar ve çalışma sonucunda mekânsal etki tespit etmişlerdir. Akıncı vd. (2017) çalışmalarında terörizmin sosyo-ekonomik belirleyicileri coğrafi ağırlıklı regresyon analizi kullanılarak araştırmışlardır.

Bu çalışmada Türkiye'de CBS yöntemleri finans alanına uygulanarak disiplinler arası farklı bir bakış açısı kazandırılmaya çalışılmıştır.

\section{YÖNTEM}

Belirlenen amaç kapsamında Türkiye'nin finansal risk yayılımının mekânsal analizleri için coğrafi ağırlıklı regresyon analizinden faydalanılmıştır. Bu bağlamda bahsedilen analiz türünde, coğrafi birimler farklı faktörler açısından birbirinden ayrılmaktadır. Bu ayrımdan dolayı değişkenler arasındaki ilişkide bölgeden bölgeye 
farklılık göstermektedir. Coğrafi ağırlıklı regresyon modelleri sayesinde farklı bölgelere ait ilişki tahmini yapılabilmektedir (Eckey vd., 2007).

Klasik lineer bir regresyon modelinde istenen " $y$ " bağımlı değişkenini açıklayan " $n$ " tane "x" bağımsız değişkeninin etki düzeyi belirlenmeye çalışlılı. Modelin parametrelerini tahmin etmek için ise genelde EKK (En küçük kareler) yöntemi kullanılır. Modelde bağımlı değişken sayısı tektir. Fakat bağımsız değişken sayısı farklı sayılarda olabilmektedir. Eğer bağımsız değişken sayısı tek ise basit bir regresyon modeli, birden fazla ise çoklu regresyon modeli ile çalışılmalıdır. Ayrıca regresyon modelinde değişkenler arasındaki ilişki doğrusal ise doğrusal bir regresyon modeli, değil ise eğrisel bir regresyon modeli baz alınır. EKK yöntemiyle elde edilen regresyon analizlerinde tüm gözlemler için tek bir sonuç elde edilir. Fakat her bir bağımsız değişkenin bağımlı değişken üzerindeki etkisi farklı mekânlardan ve diğer parametrelerden de ayrıca etkilenir. Bu farklılığı klasik regresyon modellerinde dikkate alarak modele dâhil etmek mümkün değildir.

İşte bu konum farklılıklarını dikkate alarak her bir konum için ayrı ayrı model kurarak parametre hesaplayan model coğrafi ağırlıklı regresyon modelidir. Ayrıca her bir regresyon değeri konuma dahil olan bölgelerin uzaklık veya komşuluklarına göre ağırlıklandırılır. Coğrafi ağırlıklı regresyonun klasik regresyondan en önemli farkı budur. Coğrafi ağırlıklı regresyon modeli formülü Formül (1)'de görüldüğü gibidir.

$$
Y_{i}=\beta_{0 i}+\sum_{k=1}^{n} \beta_{i k} X_{i k}+\mu_{i k}
$$

Bu formülde $\mathrm{Y}$; bağımlı değişkeni, $\mathrm{X}$; bağımsız değişkenleri $\mathbf{i} ; \mathbf{i}=1, \ldots, \mathrm{n}$ coğrafik birimi, $\beta ;(\mathrm{k}=1,2, \ldots \mathrm{n})$ lokal parametreleri, $\mu$; uzaklık katsayısını göstermektedir.

Formülde (1) görüldüğü üzere klasik regresyon modeline göre coğrafi ağırlıklı regresyon modeli her bir konum için ayrı ayrı regresyon katsayısı hesaplamaktadır. Bu model ayrıca her bir konum için hesaplanan ağırlık matrisine bağlı olarak her bir bölge için ayrı bir model kurmaktadır. Bunun sonucunda her bir konumun mekânsal dağılımının farklılığı belirlendiği gibi sonuçlar harita üzerinde de gösterilebilmektedir. Mekânsal etki, mekânsal heterojenliği ve mekânsal bağımlılığı birlikte içermektedir (Florax \& Van Der Vlist, 2003). Çalışmanın mekânsal analizleri için ArcGIS10.3 programı kullanılmıştır. ArcGIS teknolojisinde, sayısallaştıran tabletler, ekran üzerinden, asciitext dosyalarından ve farklı ortamlarda üretilmiş ve manyetik ortamda bulunan veriler dönüştürülerek veri üretimi sağlanır (Kol \& Küpçü, 2008).

Çalışmada 2016 yılına ait İstatistiki Bölge Birimleri Sınıflandırması (İBBS) düzey 2 verileri kullanılmıştır. İBBS, Türkiye'nin AB uyum sürecinde yerine getirmekle yükümlü olduğu bir kriterdir. Bu şekilde yapılacak sınıflandırmalarla bölgesel politikaların geliştirilmesi, bölgesel analizlerin yapılması ve karşılaştırılabilir istatistiki verilerin üretilmesi amaçlanmaktadır. İBBS 2 düzeyinde 26 adet bölge bulunmaktadır. Bu bölgelere ait tanımlamalar Tablo 1'de gösterilmiştir.

Tablo 1. İBBS Düzey 2 Bölgeleri

\begin{tabular}{|c|c|}
\hline Kod & İller \\
\hline TR10 & İstanbul \\
\hline TR21 & Tekirdağ, Edirne, Kırklareli \\
\hline TR22 & Balıkesir, Çanakkale \\
\hline TR31 & İzmir \\
\hline TR32 & Aydın, Denizli, Muğla \\
\hline TR33 & Manisa, Afyon, Kütahya, Uşak \\
\hline TR41 & Bursa, Eskişehir, Bilecik \\
\hline TR42 & Kocaeli, Sakarya, Düzce, Bolu, Yalova \\
\hline TR51 & Ankara \\
\hline TR52 & Konya, Karaman \\
\hline
\end{tabular}




\begin{tabular}{|c|c|}
\hline TR61 & Antalya, Isparta, Burdur \\
\hline TR62 & Adana, Mersin \\
\hline TR63 & Hatay, K. Maraş, Osmaniye \\
\hline Kod & İler \\
\hline TR71 & Kırıkkale, Aksaray, Niğge, Nevşehir, Kırşehir \\
\hline TR72 & Kayseri, Sivas, Yozgat \\
\hline TR81 & Zonguldak, Karabük, Bartın \\
\hline TR82 & Kastamonu, Çankırı, Sinop \\
\hline TR83 & Samsun, Tokat, Çorum, Amasya \\
\hline TR90 & Trabzon, Ordu, Giresun, Rize, Artvin, Gümüşhane \\
\hline TRA1 & Erzurum, Erzincan, Bayburt \\
\hline TRA2 & Ağrı, Kars, Iğdır, Ardahan \\
\hline TRB1 & Malatya, Elazı̆g, Bingöl, Tunceli \\
\hline TRB2 & Van, Muş, Bitlis, Hakkari \\
\hline TRC1 & Gaziantep, Adıyaman, Kilis \\
\hline TRC2 & Şanlıurfa, Diyarbakır \\
\hline TRC3 & Mardin, Batman, Şırnak, Siirt \\
\hline
\end{tabular}

IBBS 2 düzeyindeki illere ait finansal veriler TÜIK, TEPAV, BDDK ve TOBB'den elde edilmiştir. Bu kapsamda bölgeler düzeyinde 2016 yılına ait enflasyon oranı, işsizlik oranı, batık kredi oranı, sorunlu kredi kartı oranı, kişi başı milli gelir ve finansal risk primi verileri kullanılmıştır.

\section{BULGULAR}

Çalışmada elde edilen bulgular iki farklı başlıkta açıklanmıştır.

\subsection{Tanımsal Bulgular}

Analizde kullanılan verilere ait tanımsal bulgular Tablo 2'de gösterilmiştir.

Tablo 2. Tanımsal Bulgular

\begin{tabular}{|l|c|c|c|c|}
\hline & Min & Mak & Ort & S.S \\
\hline Enflasyon & 0,0723 & 0,093 & 0,079 & 0,043 \\
\hline KBMG & 4555 & 1833 & 9180 & 3489,4 \\
\hline Batık Kredi & 0,0246 & 0,065 & 0,038 & 0,8820 \\
\hline Sorunlu & 0,0237 & 0,046 & 0,032 & 0,0057 \\
\hline İșizlik & 0,049 & 0,286 & 0,103 & 0,0508 \\
\hline Finansal & 2,1666 & 4,000 & 2,750 & 0,4836 \\
\hline
\end{tabular}

Tablo 2'de görüldüğü gibi 2016 y1lında Türkiye'de enflasyon oranı \% 7,93'dür. Enflasyonun en düşük olduğu bölge TRB2 (Van, Muş, Bitlis, Hakkari), en yüksek olduğu bölge ise TR62 (Adana, Mersin)'dir. 2016 yllında Türkiye'de KBMG 9180 \$'dır. KBMG'nin en düşük olduğu bölge enflasyonda olduğu gibi TRB2 bölgesidir. KBMG'nin en büyük olduğu bölge ise TR10 (İstanbul) bölgesidir. İlgili dönemde batık kredilerin toplam kredilere oranı \% 3,89'dur. Batık kredi oranın en düşük olduğu bölge TR10 bölgesidir. En yüksek olduğu bölge ise TRC2 (Şanlıurfa, Diyarbakır) bölgesidir. 2016 yılında sorunlu kredi kartlarının toplam kredi kartlarına oranı \% 3,24'dür. Türkiye'de 2016 yılı işsizlik oranı \% 10,3'dür. İlgili dönemde en düşük işsizlik oranı \% 4,9 ile TR90 (Trabzon, Ordu, Giresun, Rize, Artvin, Gümüşhane) bölgesinde iken en yüksek işsizlik oranı \% 28,6 ile TRC3 bölgesinde gerçekleşmiştir. Finansal risk açısından elde edilen bulgulara göre en düşük finansal risk TR72 (Kayseri, Sivas, Yozgat) bölgesine, en büyük finansal risk ise TRC3 bölgesine aittir. 


\subsection{Mekânsal Regresyon Analiz Sonuçları}

Çalışmada kullanılan verilerin mekânsal analizleri için ArcGIS 10.3 programı kullanılmıştır. Mekânsal regresyon analiz sonuçları Tablo 3'de sunulmuştur.

Tablo 3. Mekânsal Regresyon Analiz Sonuçları

\begin{tabular}{|l|c|}
\hline \multicolumn{1}{|c|}{ Çıktı } & Değer \\
\hline Ayarlı Belirlenim Katsayısı & 0,839625 \\
\hline $\mathrm{R}^{2}$ & 0,856890 \\
\hline AICc & $-36,4848$ \\
\hline Moran's Endeksi & 0,269575 \\
\hline Varyans & 0,006851 \\
\hline Z Değeri & 3,404225 \\
\hline p Değeri & 0,000664 \\
\hline Artık Kareler & 2,416981 \\
\hline
\end{tabular}

Mekânsal otokorelasyon komşuluk değerine göre ilişkileri ortaya koymaktadır. Yakın komşuların uzak komşulara göre daha çok ilişki olduğunu ifade etmektedir. İlişki olmayan değişkenlerin arasında bir coğrafyadan söz etmek mümkün değildir. Bu bağlamda Moran's I mekânsal otokorelasyon ölçümlenmesinde kullanılan en yaygın yöntemlerden birisidir. Bu yöntem regresyon analizlerinden önce kullanılan pearson korelasyon katsayısına benzemektedir. +1 ile -1 arasında değerler olan bu indeks, negatif değerler alıyorsa komşu değişkenlerin birbirinden farklı olduğunu, pozitif değerler alıyorsa benzer bir kümelenme olduğunu göstermektedir. 0 ise değişkenlerin rassal anlamsız bir dağılım gösterdiğini belirtmektedir. Bu doğrultuda elde ettiğimiz 0,269 Moran's I değeri değişkenlerin arasında pozitif bir otokorelasyon olduğunu ve bunun 0,000 "p" değerinde anlamlı olduğunu göstermektedir. Modelin belirlilik katsayısının R2 $=0.856$ olduğu görülmektedir. Bağımlı değişken olan finansal riski, bağımsız değişkenler olan enflasyon oranı, işsizlik oranı, batık kredi oranı, sorunlu kredi kartı oranı ve kişi başı milli gelir \%85,6 oranında açıklamaktadır. Z değerinin 3,404 olması +1.96 dan yüksek olduğu için elde edilen finansal risk haritasının genel modelinin anlamlılığını ifade etmektedir. Buna paralel olarak varyans değeri de z değerinin anlamlılığını desteklemektedir. Elde edilen haritanın anlamlı bir modelden elde edildiğini göstermektedir. Bu değerlere paralel olarak, diğer parametrelerde modelin anlamlılığını destekleyici oranlardadır.

Bu açıklamalar çerçevesinde Türkiye'nin 2016 yılında CBS tabanlı finansal risk haritasına ait ArcGIS çıtısı Ek 1'de gösterilmiştir. Ek 1'de görüldüğ̈̈ gibi TR31 (İzmir) ve TR51 (Ankara) bölgeleri en yüksek riske sahip bölgeler olarak ortaya çıkmıștır. Bu sonucun ortaya çıkmasındaki en büyük etkinin enflasyon ve işsizlik oranı olduğunu söyleyebiliriz. İlgili bölgelerde enflasyon oranı yüksektir. Çalıșmada, diğer parametrelere göre finansal risk üzerinde enflasyon oranın daha yüksek etkiye sahip olduğu tespit edilmiștir. Haritaya göre TR42 (Kocaeli, Sakarya, Düzce, Bolu, Yalova) bölgesi finansal riskin en düşük olduğu bölgedir. İlgili bölgenin parametreleri incelendiğinde enflasyon oranının düşük olduğu ve milli gelir seviyenin yüksek olduğu görülmektedir. Haritada görüldüğü gibi TR10, TR21, TR32, TR61, TR63, TR83, TR90, TRA1 ve TRC3 bölgeleri orta düzeyde finansal risk derecesine sahiptir.

\section{TARTIŞMA VE SONUÇ}

CBS'nin kullanım alanları gün geçtikçe artmaktadır. İletişim, kentsel planlama, ulaşım, tarım, çevresel analizler ve afet yönetimi gibi birçok alanda CBS tabanlı uygulamalar kullanılabilmektedir. CBS, coğrafi nitelikteki bilgilerin toplanması, depolanması, işlenmesi, analizi, sunumu ve yorumlanması amacıyla donanım ve yazılım destekli sistemlerdir. Finansal bilgilerin ve analizlerin kullanıcılara ulaşması evresinde de benzer şekilde bir sistem mevcuttur. Finansal analiz yapılabilmesi için ilgili verilerin, toplanması, birleştirilmesi, işlenmesi, analiz edilmesi ve sonuçların ortaya koyularak yorumlanması esastır. Hatta birçok finansal analiz, coğrafi bölgelere ait verilerden hareketle ortaya çıkmaktadır. 
Bu noktadan hareketle çalışmada; CBS'nin finans alanında kullanılabilirliğini göstermek için Türkiye'nin 2016 yılına ait finansal risk haritasının ortaya çıkarılması amaçlanmıştır. Çalışmada finansal risk bileşenlerinden enflasyon oranı, işsizlik oranı, kişibaşı milli gelir, batık kredi oranı ve sorunlu kredi kartı değiş̧kenlerine ait İBBS 2 düzeyinde toplanarak analiz edilmiştir. İlgili dönemde Türkiye'de enflasyon oranı $\% 7,93$, işsizlik oranı $\%$ 10,3, batık kredi oranı \% 3,89, sorunlu kredi kartı oranı \% 3,23 ve kişibaşı milli gelir 9180 \$'dır. Mekânsal regresyon analiz sonuçlarına göre R2 değeri 0,856890 olarak bulunmuştur. Buna göre çalışmada kullanılan parametrelerin finansal riski açıklama oranı yaklaşık \% 86'dır. Ortaya çıkan finansal risk haritasına göre ilgili parametreler içerisinde enflasyon oranının finansal risk üzerindeki etkisinin daha yüksek olduğu görülmüştür. Elde edilen finansal risk haritasına göre TR31 (İzmir) ve TR51 (Ankara) bölgeleri en yüksek riske sahip bölgeler, TR42 (Kocaeli, Sakarya, Düzce, Bolu, Yalova) bölgesi ise en düşük riske sahip bölgedir. Bu çalışma İBBS 2 düzeyinde gerçekleştirilmiş olup, İBBS 3 düzeyinde (81 il) de gerçekleştirilebilir. Ancak il düzeyinde ilgili verileri elde etmek oldukça güçtür. Çalışmada finansal risk düzeyini belirlemede kullanılan enflasyon oranı, işsizlik oranı, kişibaşı milli gelir, batık kredi oranı ve sorunlu kredi kartı parametreleri kullanılmıştır. $\mathrm{Bu}$ parametrelere karşılıksız çek oranı, istihdama katılım oranı ve mevduatın krediye dönüşüm oranı gibi parametrelerde eklenerek analiz geliştirilebilir. Bunun yanında sadece finansal risk haritası değil, ülke veya ülkeler bazında politik risk haritaları, ekonomik risk haritaları ve ülke risk haritaları elde edilebilir. Çalışmada elde edilen sonuçlar, CBS tabanlı uygulamaların finans alanında kullanılarak dinamik ve görsel sonuçlar elde edilebileceğini göstermektedir.

\section{TEŞEKKÜR}

$\mathrm{Bu}$ çalışma 4. Uluslararası Yönetim Bilişim Kongresi'nde sunulmuş ve Gümüşhane Üniversitesi Bilimsel Araştırma Projeleri Koordinatörlüğü'nce desteklenmiştir. Proje No: 17.R0700.02.01

\section{KAYNAKLAR}

Akıncı, M. Yüce Akıncı, G. \& Yılmaz, Ö. (2017), Dramın boyutlarını ölçümü: terörizmin sosyo-ekonomik belirleyicilerinin coğrafi ağırlıklı regresyon analizi, Fiscaoeconomia, 1(3), 68-107.

Altan, M., Şekeroğlu, G., \& Karahan, N. S. (2016). Türkiye'nin Finansal Risk Haritası, Sosyal Ekonomik Araştırmalar Dergisi, (31), 203-224.

Baktemur, F. İ \& Özmen M. (2017), Gelişmiş AB ülkeleri için işsizlik yakınsamasının mekansal ekonometrik analizi, Finans Politik \& Ekonomik Yorumlar, 54(626), 33-45.

Cecchetti, S. G., Fender, I., \& McGuire, P. (2010). Toward a global risk map. Bank for International Settlements. No: 309.

Colletaz, G., Hurlin, C., \& Pérignon, C. (2013). The Risk Map: A new tool for validating risk models. Journal of Banking \& Finance, 37(10), 3843-3854

Çelik, N. (2017). Teşvik politikalarının etkinliğinin mekansal perspektiften değerlendirilmesi, Ege Akademik Bakış, 17(1), 1-12.

Eckey, H. F., Kosfeld, R., \& Türck, M. (2007). Regional convergence in Germany: a geographically weighted regression approach. Spatial Economic Analysis, 2(1), 45-64.

Florax, R. J., \& Van Der Vlist, A. J. (2003). Spatial econometric data analysis: Moving beyond traditional models. International Regional Science Review, 26(3), 223-243.

Hoti, S. \& McAleer, M. (2005). Modelling the riskiness in country risk ratings. Netherlands: Elsevier Ltd.

Jones, C. P. (1998) Investment, Analysis and Managemenet (Sixth Edition). New York: John Wiley \& Sons Inc.

Kol, Ç., \& Küpçü, S. (2008). ArcGIS Spatial Analiz. Ankara: İşlem Coğrafi Bilgi Sistemleri Mühendislik ve Eğitim Ltd. Şti.

Modigliani, F., \& Fabozzi, F. J. (1992). Capital Markets: institutions and instruments.NJ: Prentice Hall Inc.

Okka, O. (2010). Finansal yönetim: teori ve çözümlü problemler. Ankara: Nobel Basım Dağıtım.

Peggion, M., Bernardini, A., \& Masera, M. (2008). Geographic information systems and risk assessment. Scientific and Technical Research series EUR, Luxembourg: Office for Official Publications of the European Communities.

Yomralioglu, T. (2002). GIS activities in Turkey. In Proceedings of international symposium on GIS (pp. 834-840).

$\mathrm{Bu}$ çalışma 4. Uluslararası Yönetim Bilişim Sistemleri konferansında sunularak, özeti konferans özet kitabında yayınlanmıştır. 
Ek 1. Türkiye Finansal Risk Haritası (2016)

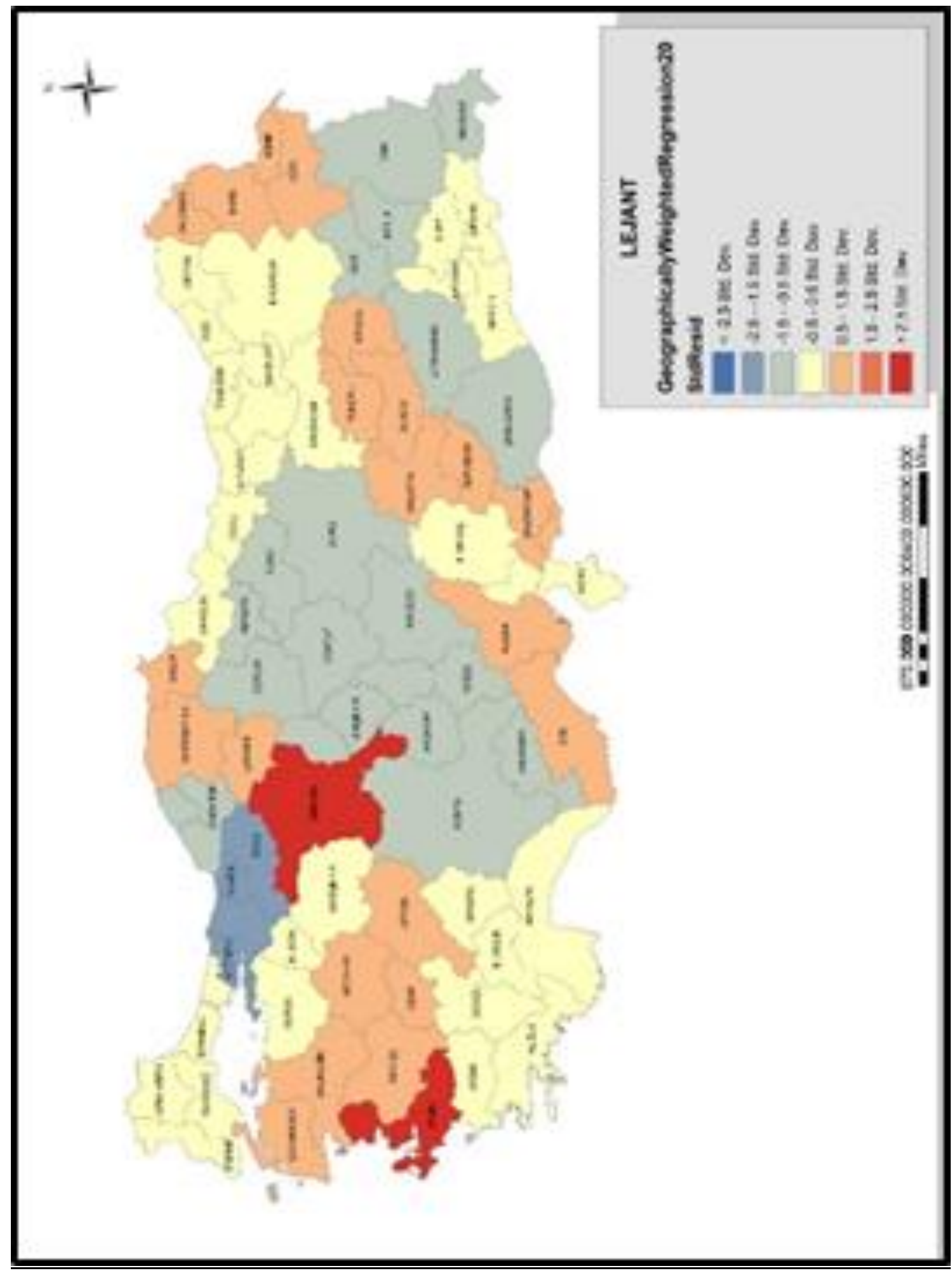

